\title{
Determination and Comparison of Trace Elements in Various Parts of Eichhornia crassipes by a Validated Method using Inductively Coupled Plasma Mass Spectrometry and Atomic Emission Spectrometry
}

\author{
Deepti Gholap Khanvilkar ${ }^{\dagger \oplus} \cdot$ Simran Nagarjee
}

Bharati Vidyapeeth Deemed University, R\&D Centre in Pharmaceutical Sciences and Applied Chemistry, Poona College of Pharmacy, Pune, 411038, India

(Received July 28, 2020; Revised September 15, 2020; Accepted October 19, 2020)

Objective : In this study, we have evaluated trace element concentration of various parts of Eicchornia crassipes, collected from three different lakes in Pune district, India.

Methods: The dried segregated parts of Eicchornia crassipes were subjected to microwave digestion, followed by measurement with Inductively Coupled Plasma-Optical Emission Spectroscopy (ICP-OES) and Inductively Coupled Plasma-Mass Spectroscopy (ICP-MS). Optimization and validation of the method was performed for determining the minor and trace element concentrations of $\mathrm{Co}, \mathrm{I}, \mathrm{Ni}, \mathrm{Cu}, \mathrm{Mn}, \mathrm{Zn}, \mathrm{Fe}$ in roots, petiole and leaves of the plant. NIST Standard reference material SRM 1547 (Peach leaves) was used for establishing accuracy of the analytical method. Rhodium was used an internal standard for correcting matrix effects.

Results and Discussion: A validated ICP-OES and ICP-MS method was established for determining the minor and trace element concentrations of $\mathrm{Co}, \mathrm{I}, \mathrm{Ni}, \mathrm{Cu}, \mathrm{Mn}, \mathrm{Zn}, \mathrm{Fe}$ in roots, petiole and leaves of the plant. Levels of all elements were found to be higher in roots, followed by petiole and leaves. Except for $\mathrm{Zn}$ and $\mathrm{Fe}$, where concentration in leaves was found to be higher than in petiole. Of all the measured elements, total concentration of Mn was found to be highest $\left(566 \mathrm{mg} \mathrm{kg}^{-1}\right)$, followed by $\mathrm{Fe}\left(341 \mathrm{mg} \mathrm{kg}^{-1}\right), \mathrm{Zn}\left(40.26 \mathrm{mg} \mathrm{kg}^{-1}\right), \mathrm{Cu}(28.04 \mathrm{mg}$ $\left.\mathrm{kg}^{-1}\right)$, Ni $\left(9.54 \mathrm{mg} \mathrm{kg}^{-1}\right)$, Co $\left(4.33 \mathrm{mg} \mathrm{kg}^{-1}\right)$ and I $\left(0.94 \mathrm{mg} \mathrm{kg}^{-1}\right)$. A surprising finding was the presence of iodine in the plant, despite its non-marine source.

Conclusion: Plant-derived products form an important category in alternative medicine that is often used for treatment of several disorders. Eicchornia crassipes (water hyacinth), considered as the world's worst weed, has been used in folk medicine, with very little evidence-based data to support its potential medicinal value. Here we report the trace element profile of Eicchornia crassipes. Insight into the trace element profile of various parts of the plant can perhaps be harnessed to postulate the rationale behind the use of specific parts of the weed in traditional medicine.

Keywords: Trace Elements, ICP-MS, ICP-OES, Eichhornia Crassipes 


\section{Introduction}

Eichhornia crassipes, commonly known as water hyacinth, is an aquatic floating macrophyte, native to the Amazon basin. The plant is hardy and very difficult to eradicate because it can survive extremely harsh conditions. It can absorb into its tissues large quantities of minerals from the water column. Plant and plant derived products form an important alternative medicine category in health care that are often used for treatment of several disorders. According to folk medicine, Eichhornia crassipes has been used for treatment of several aliments. In Java, green parts, inflorescences and flowers spikes are cooked and eaten. There are reports of its use as a styptic in Chhattisgarh, India. The fresh juice of this weed is used to treat fresh wounds as the tribes believe that it stops further spread of infection and relieves stress associated with the injury. Along with vinegar, it has been reported to use in treatment of septic wounds. ${ }^{1)}$ Eichhornia crassipes has also been used to ease swelling, burning, haemorrhage, and goiters. In India and Nigeria, the oil from flowers has been used for skin care as well as for treatment of skin diseases. ${ }^{2)}$ In Assam, the flowers and roots have been used in treatment of stomach ache and pneumonia. In Bangladesh, the plant has been used in treating hepatic disorders. ${ }^{3)}$ In recent years, there are reports of Eichhornia crassipes being used as an insecticide, antioxidant, antitumor, antiinflamoatory and as an antimicrobial agent. $^{4-6)}$

Trace elements constitute less than $0.01 \%$ of the weight of the human body; however, despite their relative scarcity, they play an important role in human growth and development deficiency or excess of trace elements are associated with several metabolic disorders. An investigation focusing to understand the relationship between trace elements and human health has led to the conquest of diseases such as pernicious anaemia and recently, Keshan disease.

The purpose of this study is to determine the distribution of trace elements in different parts of the Eichhornia crassipes. It is expected that the metal distribution within the plant species would be a representation of the concentration of the water in which it is found. Majority of available literature on water hyacinth is focused on its potential in phytoremediation, as a source of cellulose for paper production or as a source of cattle feed/fish feed. The plant has been exploited only to a certain extent in terms of its phytochemical uses. ${ }^{7)}$ A more systematic investigation needs to undertaken to exploit the ability of Eichhornia crassipes to accumulate non-essential and essential trace elements in order to investigate its potential for specific pharmaceutical or cosmeceutical studies like diarrhoea, skin burns, antibacterial agent, goiter etc. ${ }^{8-11)}$ Although, only elemental analysis data is insufficient to decode the mechanisms involved in the use of Eichhornia crassipes in folk medicine, and a more detailed study needs to be undertaken with respect to its secondary metabolite profiling. Nevertheless, insight into the trace element concentration of this plant can perhaps be harnessed to postulate the rationale behind its use in traditional medicine. The occurance of high levels of trace elements in Eichhornia crassipes could perhaps motivate government or private sectors to invest in the removal of the weed and use it for extraction of the trace elements for commercial purpose. This is the first study reporting concentration levels of trace elements in Eichhornia crassipes, particularly from India.

\section{Materials and Methods}

\subsection{Collection of plant material}

Eicchornia crassipes was collected in the month on March 2018 from three different locations across Pune district, viz, Pashan Lake, Mula river, Mutha river, Pune, India. The samples were authenticated by department of pharmacognosy, Poona College of Pharmacy, India. The leaves, petioles and roots of the plant were segregated and set to dry under shade for 15 days until constant weight of the dry mass was obtained. The dried samples were then ground to fine powder.

\subsection{Sample preparation and digestion}

The samples were separately weighed, following which they were subjected to microwave digestion (Mars Express Vessel) according to the parameters given in Table 1.

For digestion, $0.5 \mathrm{~g}$ of sample was taken into a digestion vessel to which $3 \mathrm{~mL}$ of nitric acid $\left(\mathrm{HNO}_{3} 69 \%\right.$ Suprapure grade), $7 \mathrm{~mL}$ of hydrochloric acid (HCL 30\% Suprapure grade) was added. Blank solutions were prepared similarly. Digested samples were transferred to falcon tubes and diluted with acidified water to a volume of $50 \mathrm{~mL}$. The resulting solutions were subjected to Inductively Coupled Optical Emission Spectroscopy (ICP-OES) and Inductively coupled Plasma Mass Spectrometry (ICP-MS) analysis.

Table 1. Operating conditions for the microwave digestion system.

\begin{tabular}{ccccc} 
Step & Power & Temperature & Ramp time & Hold time \\
1 & $1,500 \mathrm{~W}$ & $170^{\circ} \mathrm{C}$ & $15 \mathrm{~min}$ & $15 \mathrm{~min}$ \\
\hline
\end{tabular}




\section{3. lodine sample preparation}

For Iodine determination, $0.5 \mathrm{~g}$ of the sample was digested in basic medium by taking $1 \mathrm{~mL}$ tetra methyl ammonium hydroxide (TMAH) to which $5 \mathrm{~mL}$ of water was added. The solution was subjected to centrifugation, after which it was kept in oven for $2 \mathrm{~h}$ at $80^{\circ} \mathrm{C}$. The final volume was made up to $50 \mathrm{~mL}$ water.

\subsection{Standard preparation}

Stock solutions containing 1,000 mg/L of Perkin Elmer Pure was used to prepare different custom-grade multielement standard solutions for $\mathrm{Co}, \mathrm{I}, \mathrm{Se}, \mathrm{Ni}, \mathrm{Cu}, \mathrm{Mn}, \mathrm{Zn}, \mathrm{Fe}$ by diluting with $50 \mathrm{~mL}$ acidified water. Calibration curves for each element were constructed in triplicate using six different concentration. An internal-standard stock solution containing $100 \mu \mathrm{g} / \mathrm{L}$ of rhodium (Rh) was prepared from single-element stock solutions. NIST Standard reference material SRM 1547 (Peach leaves) was used for establishing accuracy of the analytical method. Suprapure grade nitric acid and hydrochloric acid were used for preparing stock solutions of $100 \mu \mathrm{g} / \mathrm{mL}$ and $10 \mu \mathrm{g} / \mathrm{mL}$ for ICP-OES and ICP-MS respectively.

\subsection{ICP-OES and ICP-MS analysis}

Initially, the sample digests were subjected to a semi-quantitative analysis which allowed the establishment of the range of concentrations of the elements in the various digestion solutions. The error associated with the semiquantitative analysis was calculated to approximately $25 \%$. Based on the results obtained, the elements were divided into two groups depending on the determined concentrations. Group 1 elements $(\mathrm{Co}, \mathrm{Ni}, \mathrm{Cu}, \mathrm{I})$ were determined by ICP-MS (Agilent 7700 series) and group 2 elements (Mn, Zn, Fe) were subjected to ICP-OES (Thermo Fisher Scientific, Bremen Germany, i CAP 6300) analysis. The quantitative determinations were carried out by a calibration curve using multielement standard solutions in which the concentrations of the elements were in an optimal measurement range.

\section{Result and Discussion}

\subsection{Choice of isotopes and correction of interferences}

After careful evaluation of all possible isotopes, their abundances, potential interferences (meaningful in the analysis of plants) and the corrections introduced, isotopes selected for quantitative estimation of the respective elements were; ${ }^{59} \mathrm{Co}$, ${ }^{127} \mathrm{I},{ }^{60} \mathrm{Ni},{ }^{66} \mathrm{Cu}$. Pure single element standard solutions of the interfering elements were used to establish the actual interferences on all isotopes under investigation.

The corrections were calculated ${ }^{12)}$ according to Eq. (1).

$$
\mathrm{S}_{\text {cor }}=\mathrm{S}_{\text {meas }}-\left(\mathrm{S}_{\text {inter }} \mathrm{A}\right)
$$

Where $\mathrm{S}_{\text {cor }}$ is the corrected signal of the analyte; $\mathrm{S}_{\text {meas }}$ is the measured signal; $S_{\text {inter }}$ is the signal of the interfering element and $\mathrm{A}$ is the $\%$ of formation of the respective interfering species determined in the solution of the interfering element at the working conditions specified in Table 2 and Table 3. $S_{\text {inter }}$ is measured in each sample and the isotope abundance is accounted for.

\subsection{Element concentration}

The concentration values of $\mathrm{Co}, \mathrm{I}, \mathrm{Se}, \mathrm{Ni}, \mathrm{Cu}, \mathrm{Mn}, \mathrm{Zn}, \mathrm{Fe}$ in various parts like roots, leaves and petiole as expressed in $\mathrm{mg} / \mathrm{Kg}$ are given in Table 4. The total range of concentration of elements was found as low as $0.94 \mathrm{mg} / \mathrm{Kg}$ for I and as high as $566 \mathrm{mg} / \mathrm{Kg}$ for $\mathrm{Mn}$. The order of overall mean concentration of trace elements in Eichhornia crassipes was

Table 2. Instrumental analytical conditions for ICP-OES of element analysis.

\begin{tabular}{cc} 
Parameter & Settings \\
Pump rate & 50 \\
\hline RF power & $1,150 \mathrm{~W}$ \\
\hline Plasma view & Axial \\
\hline Auxillary gas flow & $0.5 \mathrm{~L} \mathrm{~min}^{-1}$ \\
\hline Nebuliser gas (Argon) & $0.5 \mathrm{~L} \mathrm{~min}^{-1}$ \\
\hline Stabilisation time & $10 \mathrm{~min}^{-1}$ \\
\hline Plasma gas & $12 \mathrm{~L} \mathrm{~min}^{-1}$
\end{tabular}

Table 3. Optimised instrumental parameters for element analysis of samples and standards using ICP-MS.

\begin{tabular}{cc} 
Parameter & Settings \\
RF power & $1,550 \mathrm{~W}$ \\
\hline RF matching & $1.00 \mathrm{Volts}$ \\
\hline Sample depth & $8 \mathrm{~mm}$ \\
\hline Carrier gas (Argon) & $0.99 \mathrm{~L} \mathrm{~min}^{-1}$ \\
\hline Scanning time & $2 \mathrm{~min}$ \\
\hline Pump speed & $0.5 \mathrm{rpm}$ \\
\hline Plasma gas flow & $0.5 \mathrm{~L} \mathrm{~min}^{-1}$ \\
\hline Auxillary gas flow & $0.5 \mathrm{~L} \mathrm{~min}^{-1}$ \\
\hline Nebuliser gas flow & $0.5 \mathrm{~L} \mathrm{~min}^{-1}$ \\
\hline Sweeps/ reading & 100 \\
\hline Scan mode & No gas mode \\
\hline Run time & 3 min
\end{tabular}


Table 4. Unspiked trace element concentration in Eicchornia crassipes.

\begin{tabular}{ccccc} 
Element & Roots & Petiole & Leaves & Total \\
${ }^{59} \mathrm{Co}^{*}$ & $4.06 \pm 0.04$ & $0.13 \pm 0.02$ & $0.14 \pm 0.02$ & $4.33 \pm 0.02$ \\
\hline${ }^{127} \mathrm{I}^{*}$ & $0.37 \pm 0.01$ & $0.21 \pm 0.01$ & $0.36 \pm 0.01$ & $0.94 \pm 0.01$ \\
\hline${ }^{60} \mathrm{Ni}^{*}$ & $7.42 \pm 0.1$ & $1.1 \pm 0.01$ & $0.97 \pm 0.01$ & $9.54 \pm 0.01$ \\
\hline${ }^{66} \mathrm{Cu}^{*}$ & $19.1 \pm 0.1$ & $7.5 \pm 0.02$ & $1.38 \pm 0.05$ & $28.04 \pm 0.1$ \\
\hline $\mathrm{Mn}^{* *}$ & $445 \pm 0.4$ & $69.6 \pm 0.8$ & $51.3 \pm 0.15$ & $566 \pm 0.16$ \\
\hline $\mathrm{Zn}^{* *}$ & $24.5 \pm 0.5$ & $4.3 \pm 0.2$ & $11.3 \pm 0.15$ & $40.26 \pm 0.07$ \\
\hline $\mathrm{Fe}^{* *}$ & $313 \pm 1.2$ & $8.96 \pm 0.4$ & $18.9 \pm 0.17$ & $341 \pm 0.64$ \\
\hline
\end{tabular}

* Elements measured by ICP-MS, ${ }^{* *}$ Elements measured by ICP-OES. Concentrations of all elements are in mg/Kg.

found as $\mathrm{Mn}>\mathrm{Fe}>\mathrm{Zn}>\mathrm{Cu}>\mathrm{Ni}>\mathrm{Co}>\mathrm{I}$. Roots of the plant are in direct contact with the surrounding water and as a result they form the principle part of element uptake. Concentration of all measured elements was found to highest in roots. The concentration of $\mathrm{Ni}, \mathrm{Cu}, \mathrm{Mn}$, was found to be highest in Roots $>$ Petiol $>$ Leaves. Whereas, the concentration of $\mathrm{Zn}$ and Fe was found to be highest in roots followed by leaves and petiole. This finding suggests alteration in transport mechanism or storage process involved with $\mathrm{Zn}$ and Fe. More detailed studies involving 2D-element mapping are necessary to evaluate the transport and storage mechanism of these elements in Eichhornia crassipes. Concentration of Co was high in roots but in petiole and leaves it was almost similar. An interesting finding was the occurrence of measurable quantities of Iodine in all the parts of the plant despite its non marine source. Occurrence of measureable Iodine in ecosystems far from seashores is not a rare phenomenon. Although high levels of iodine invariably occur in vicinity of costal zones, nevertheless, there is no simple correlation between distance from shoreline and content of iodine in a sample. Among many factors that influence the level of iodine in a sample, supply of iodine, sample's iodine fixation potential and adsorption of atmospheric iodine on plant's surface are some important contributors. ${ }^{13)}$ This data shows that amongst all measured elements, Eichhornia crassipes is exhibited highest bioaccumulation for Mn. This finding is in agreement with another similar study done by Olutona et al. ${ }^{14)}$

\subsection{Recovery}

Recovery value of an analytical method, is a parameter that signifies accuracy of the adopted analytical process. Accuracy is defined as the closeness between the true value of the analyte in the sample and the experimentally obtained value by following the prescribed analytical procedure. A good recovery value ensures that no significant loss or contamination has occurred during the test procedure.
To establish accuracy of the method, certified reference standard SRM 1547 (Peach leaves) was measured and concentration of the desired elements were determined using both ICP-MS and ICP-OES. Good agreement between certified values and measured values was observed (Table 6). This demonstrates the appropriateness of the proposed method for applicability in routine element determination in plant samples.

Recovery values for the desired elements were also calculated in the digested plant samples of leaves, roots and petiole after spiking with $100 \%$ of the target limit by standard element solution.

The recovery values obtained for all the measured elements in different parts of Eichhornia crassipes, are shown in Table 7. Recovery values obtained were in between $95 \%$ to $101 \%$.

\subsection{Limits of detection and quantification}

The calibration curves for all the analytes were built on six different concentrations and LOD and LOQ values were determined.

The limits of detection (LOD) were calculated by taking three times the standard deviation of the 10 individually prepared blank solutions.

The limits of quantification (LOQ), were calculated by taking ten times the standard deviation of the 10 individually prepared blank solutions. ${ }^{8)}$ LOD and LOQ values for the measured elements are given in Table 5.

\subsection{Linearity}

The correlation coefficients were calculated for the calibration curves for all the seven trace elements on six standard replicates for six different concentrations (Fig. 1). Concentration used for determining linearity were between $10 \%$ to $120 \%$ of the target limit for each element in the final analysis solution. $\mathrm{R}^{2}$ values for the individual elements are shown in Table 5. Good correlation was obtained for all the measured elements. Observed $\mathrm{R}^{2}$ values were in the 
Table 5. Parameters of calibration obtained external calibration, correlation coefficient $\left(R^{2}\right)$, limit of detection (LOD) and limit of quantification (LOQ) by using ICP-OES and ICP-MS.

\begin{tabular}{ccccc} 
Elements & Linear equation & $R^{2}$ & LOD $\left(\mathrm{ng} \mathrm{mL}^{-1}\right)$ & LOQ $\left(\mathrm{ng} \mathrm{mL}^{-1}\right)$ \\
$\mathrm{Co}$ & $\mathrm{y}=24,783 \mathrm{x}-15714$ & 0.9986 & 0.0018 & 0.055 \\
\hline $\mathrm{I}$ & $\mathrm{y}=2801432 \mathrm{x}+1799$ & 0.9299 & 0.0019 & 0.00801 \\
\hline $\mathrm{Ni}$ & $\mathrm{y}=7339 \mathrm{x}-5023.8$ & 0.9976 & 0.026 & 0.780 \\
\hline $\mathrm{Cu}$ & $\mathrm{y}=31,295 \mathrm{x}+117.87$ & 1 & 0.25 & 0.85 \\
\hline $\mathrm{Zn}$ & $\mathrm{y}=94,308 \mathrm{x}+1164$ & 0.9998 & 0.049 & 0.16 \\
\hline $\mathrm{Fe}$ & $\mathrm{y}=19,802 \mathrm{x}+3.3093$ & 1 & 0.055 & 0.18 \\
\hline
\end{tabular}

Table 6. Assessment of method accuracy by measurement of desired trace element concentrations in certified reference material.

\begin{tabular}{cccc} 
& \multicolumn{2}{c}{ Concentration $x \pm$ SD $(\mathrm{mg} / \mathrm{Kg})$} & \multicolumn{2}{c}{ Recovery $(\%)$} \\
\cline { 2 - 4 } Element & Certified concentration & Determined value & 97 \\
\hline $\mathrm{N}$ & 0.07 & 0.068 & 96 \\
\hline $\mathrm{Nu}$ & 0.30 & 0.28 & 101 \\
\hline $\mathrm{Mn}$ & 0.68 & 0.69 & 101 \\
\hline $\mathrm{Zn}$ & 3.75 & 3.80 & 99 \\
\hline $\mathrm{Fe}$ & 97.8 & 18.10 & 101 \\
\hline
\end{tabular}

Table 7. Recovery values obtained for desired trace element concentrations in spiked sample solutions.

\begin{tabular}{|c|c|c|c|c|c|c|c|}
\hline \multirow{3}{*}{ Element } & \multicolumn{6}{|c|}{ Concentration $\mathrm{x} \pm \mathrm{SD}(\mu \mathrm{g} / \mathrm{g})$} & \multirow{3}{*}{$\begin{array}{c}\text { Recovery ( } \% \\
\text { Average }\end{array}$} \\
\hline & \multicolumn{3}{|c|}{ Spiked concentration } & \multicolumn{3}{|c|}{ Measured concentration } & \\
\hline & Roots & Petiole & Leaves & Roots & Petiole & Leaves & \\
\hline Co & 4 & 0.1 & 0.1 & 8.16 & 0.231 & 0.242 & 101 \\
\hline 1 & 0.5 & 0.2 & 0.2 & 0.81 & 0.39 & 0.54 & 95 \\
\hline $\mathrm{Ni}$ & 5 & 1 & 1 & 12.51 & 2.11 & 1.98 & 101 \\
\hline $\mathrm{Cu}$ & 20 & 10 & 1 & 40.18 & 17.64 & 2.4 & 101 \\
\hline $\mathrm{Mn}$ & 500 & 50 & 50 & 944 & 118 & 101 & 99 \\
\hline $\mathrm{Zn}$ & 25 & 5 & 10 & 48.38 & 9.4 & 20.8 & 99 \\
\hline $\mathrm{Fe}$ & 300 & 10 & 20 & 600 & 18.9 & 39.1 & 100 \\
\hline
\end{tabular}

range of 0.9976 to 1 .

\section{Conclusion}

Eichhornia crassipes has been long regarded as an invasive weed. Majority of available literature on water hyacinth is focused on its potential in phytoremediation, as a source of cellulose for paper production or as a source of cattle feed/fish feed. The plant has been exploited only to a certain extent in terms of its phytochemical uses. We believe our understanding of this plant is still relatively weak, which is limiting its appropriate management. By performing this study, we have attempted to begin to decode the use of this plant in folk medicine by correlating it use to the occurrence and content of trace elements in various parts. Minor and trace element analysis of the plant will provide evidence based rationale behind the use of Eichhornia crassipes in treatment of various aliments like goiter, antimicrobial, anti-inflammatory, antioxidant, which will present the basis for its potential use in modern treatment.

In this study a validated ICP-OES and ICP-MS method was established for determining the minor and trace element concentrations of $\mathrm{Co}, \mathrm{I}, \mathrm{Ni}, \mathrm{Cu}, \mathrm{Mn}, \mathrm{Zn}, \mathrm{Fe}$ in roots, petiole and leaves of the plant. Levels of all elements were found 


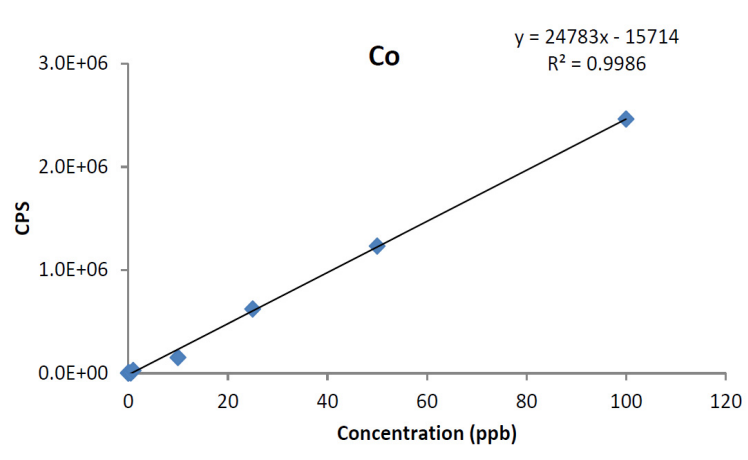

$\mathrm{Ni}$

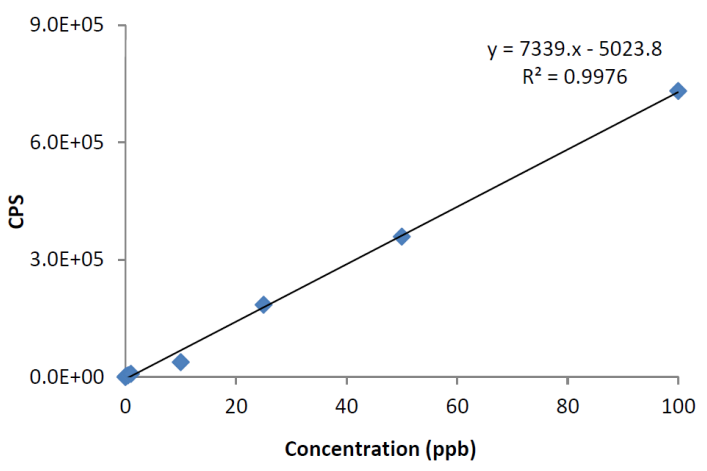

Mn

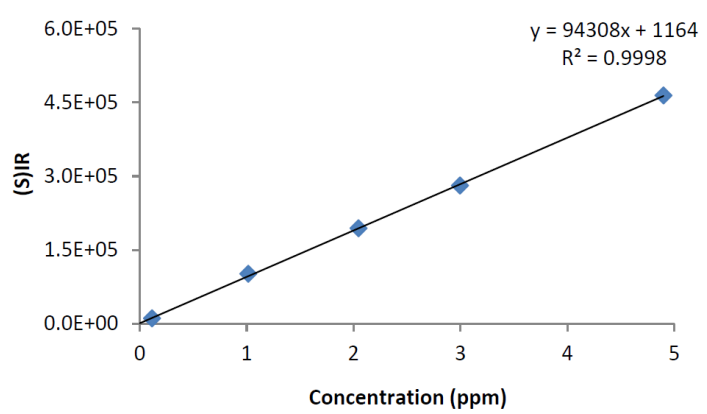

$\mathrm{Fe}$

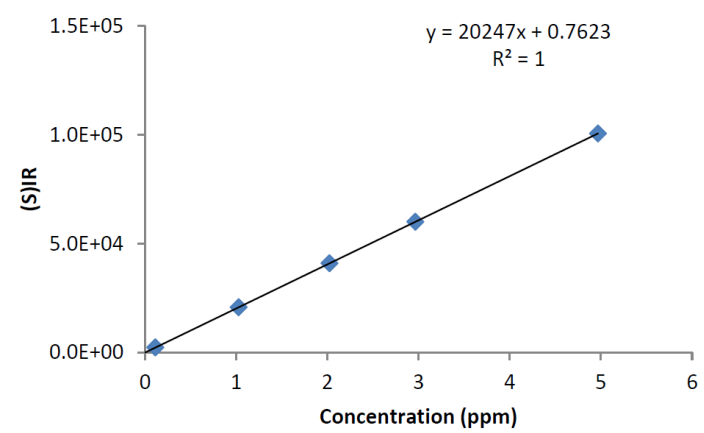

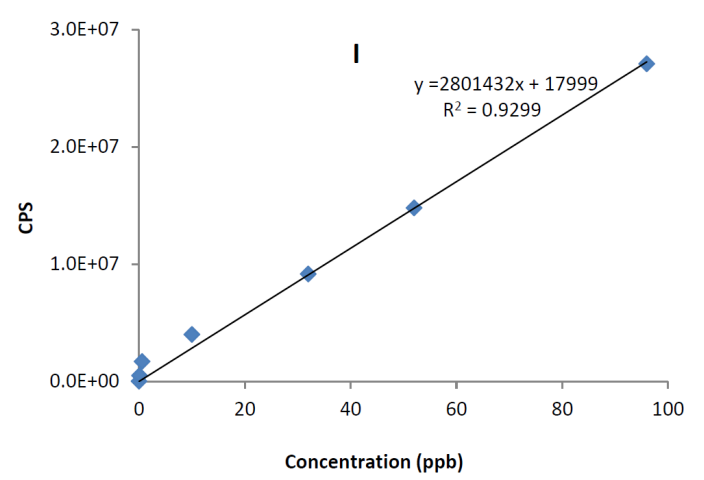

$\mathrm{Cu}$

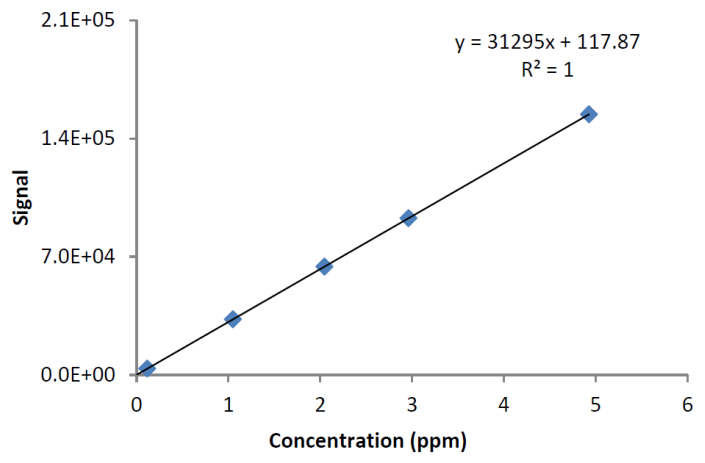

Zn

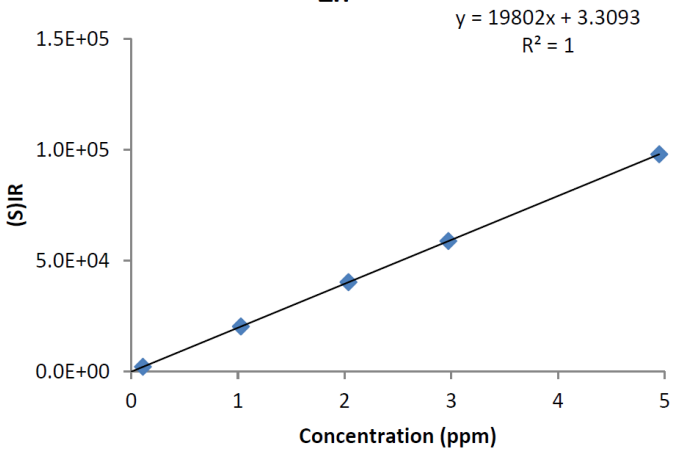

Fig. 1. Calibration plots for standard element solutions as measured using ICP-MS and ICP-OES.

to be higher in roots, followed by petiole and leaves. Except for $\mathrm{Zn}$ and $\mathrm{Fe}$, where concentration in leaves was found to be higher than in petiole. Of all the measured elements, total conentration of Mn was found to be highest (566 mg kg-1), followed by $\mathrm{Fe}\left(341 \mathrm{mg} \mathrm{kg}{ }^{-1}\right), \mathrm{Zn}\left(40.26 \mathrm{mg} \mathrm{kg}^{-1}\right), \mathrm{Cu}$
(28.04 mg kg-1), Ni (9.54 mg kg-1), Co (4.33 $\left.\mathrm{mg} \mathrm{kg}^{-1}\right)$ and I (0.94 mg kg-1).

Presence of iodine in the plant although surprising, provides rational for the use of this plant in treatment of goiter. High concentration of $\mathrm{Mn}, \mathrm{Cu}$, in the plant explanis 
could explain its use as antioxidant, antibacterial agent respectively.

Eichhornia crassipes can be thus be considered as potential source of nutrition and mineral supplements. However, the mineral composition of the plant obtained here was based on chemical analysis only. Biological evaluation using human and animal feeding studies would be required to establish the nutritional value of this plant as a source of minerals. Although we are fully aware that it has been widely acknowledged that this plant accumulates heavy metals from contaminated water sources, if the utility of the plant in pharmaceuticals/cosmeceuticals is established, it would be worthwhile to cultivate this rapidly reproducing plant in neutral water bodies for this purpose. A more detailed scientific protocol for evaluation of Eichhornia crassipes with respect to its phytochemical composition and pharmacological/cosmeceutical activity evaluation along with secondary metabolite profiling, is under process by the authors. With more such studies, a plant that has been considered a threat to the environment and economy, could be constructively harvested.

\section{References}

1. P. Oudhia, A. R. Pal, G. P. Pali, Traditional medicinal knowledge about common crop weeds in Bagbahera (India) region: a survey, Agric. Sci. Digest., 22(1), 53-54(2002).

2. J. U. Stuart, Water hyacinth, Philippine medicinal plant, http://www.stuartxchange.org/WaterHyacinth.html, June(2019).

3. P. Jayanthi, P. Lalitha, R. Sujitha, A. Thamaraiselvi, Anti-inflammatory activity of the various solvent extracts of Eichhornia crassipes (Mart.) Solms, Int. J. Pharm. Tech. Res., 5(2), 641-645(2013).

4. P. Jayanthi, P. Lalitha, Antimicrobial activity of solvent extracts of Eichhornia crassipes (Mart.) Solms, Der. Pharm. Chem., 5(3), 135-140(2013).

5. C. Liu, G. Zhao, Y. Li, Z. Ding, Q. Liu, J. Li, Contribution of phenolics and flavonoids to anti-oxidant activity of ethanol extract from Eichhornia crassipe, Adv. Mat. Res., 156-157, 1372-1377(2010).

6. H. Ali, M. Patel, N. Ganesh, J. Ahi, The world's worst aquatic plant as a safe cancer medicine-antitumor activity on melanoma induced mouse by Eichhornia crassipes: in vivo studies, J. Pharm. Res., 2(8), 1365-1366(2009).
7. T. Odugbemi, A Textbook of Medicinal Plants from Nigeria, University of Lagos Press, Lagos, Nigeria, pp. 542(2008).

8. M. El-Ghani Abd, Traditional medicinal plants of Nigeria: an overview, Agric. Biol. J. N. Am., 7, 220-247(2016).

9. R. Djingova, H. Heidenreich, P. Kovacheva, B. Markert, On the determination of platinum group elements in environmental materials by inductively coupled plasma mass spectrometry and microwave digestion, Anal. Chim. Acta, 489(2), 245-251(2003).

10. S. M. M. Shanab, E. A. Shalaby, D. A. Lightfoot, H. A. El-Shemy, Allelopathic effects of water hyacinth (Eichhornia crassipes), PLoS One, 5(10), e13200(2010).

11. C. Daniel, K. Nehru, M. Sivakumar, Rapid biosynthesis of silver nanoparticles using Eichornia crassipes and its antibacterial activity, Curr. Nanosci., 8(1), 125-129(2012).

12. R. S. Nascimento, D. B. C. Mendes, J. M. G. Matos, J. C. Silva, V. S. T. Ciminelli, W. B. Neto, Determination of trace elements in Brazilian human milk by quadrupole inductively coupled plasma mass spectrometry and microwave assisted digestion, At. Spectrosc., 29(2), 77-81(2008).

13. C. C. Johnson, The geochemistry of iodine and its application to environmental strategies for reducing the risks from iodine deficiency disorders, British Geological Survey Commissioned Report, pp. 1-41(2003).

14. G. O. Olutona, O. R. Ishola, O. E. Atobatele, Trace metal assessment in water hyacinth (Eichhornia crassipes)-Infested reservoir: a study of Awba reservoir, Ibadan, Nigeria, Terr. Aquatic Environ. Toxicol., 5(1), 25-30(2011).

\section{Authors}

\section{Deepti Gholap Khanvilkar}

Bharati Vidyapeeth Deemed University, R\&D Centre in Pharmaceutical Sciences and Applied Chemistry, Poona College of Pharmacy, Pune, 411038, India, Scientist, ORCID (1) 0000-0003 $-1536-2277$

Dr. Deepti Khanvilkar was involved in conceptualization of the project, defining the methodology involved, validation of the results and preparation of the manuscript.

\section{Simran Nagarjee}

Bharati Vidyapeeth Deemed University, R\&D Centre in Pharmaceutical Sciences and Applied Chemistry, Poona College of Pharmacy, Pune, 411038, India, Research Student Simran Nagarjee contributed by performing the experimental work in volved in the project and doing the literature survey. 